\title{
Identificação de genótipos de feijão-caupi tolerantes a salinidade avaliado por meio de método multivariado
}

\author{
Identification of tolerant cowpea genotypes to salinity evaluated by the multivariate method
}

\author{
Wener Santos de Almeida ${ }^{I^{*}}$ Francisco Ronaldo Fernandes Belém \\ Cândida Hermínia Campos de Magalhães Bertini ${ }^{I}$ Marcelo de Souza Pinheiro ${ }^{\mathrm{I}}$ Elizita Maria Teófilo
}

\section{RESUMO}

Objetivou-se com este trabalho identificar genótipos tolerantes ao estresse provocado pela solução de $\mathrm{NaCl}$ e pela mistura de $\mathrm{NaCl}, \mathrm{CaCl}_{2}$ e $\mathrm{MgCl}_{2}$ na água de irrigação, nos estádios iniciais de desenvolvimento. Os níveis de condutividade elétrica do extrato de saturação foram: 0 , 2,5; 5,0 e 7,5dS $\mathrm{m}^{-1}$. A tolerância do feijão-caupi foi avaliada através da redução relativa de matéria seca da parte aérea de cada genótipo. O genótipo CE-182 mostrou-se mais tolerante nos níveis 2,5; 5,0 e 7,5dS $\mathrm{m}^{-1}$ na água salinizada com solução de $\mathrm{NaCl}$. Na solução de mistura dos sais, os genótipos CE-9 e CE-551 foram os mais tolerantes. De acordo com os resultados obtidos pelo agrupamento, utilizando-se o método hierárquico UPGMA, verifica-se que as combinações mais promissoras para cruzamentos e obtenção de progênies superiores no desenvolvimento de cultivares tolerantes à salinidade foram entre os genótipos CE-182 e CE-250 e entre CE-551 e CE-09.

Palavras-chave: Vigna unguiculata, variabilidade genética, análise multivariada.

\section{ABSTRACT}

The objective of this research was to identify genotypes tolerant to stress caused by $\mathrm{NaCl}$ and the mixture of $\mathrm{NaCl}, \mathrm{CaCl}_{2}$ and $\mathrm{MgCl}_{2}$ in irrigation water in the early stages of development. The levels of electrical conductivity of saturation extract were 0, 0.25, 5.0 and $7.5 \mathrm{dS} \mathrm{m} \mathrm{m}^{-1}$. The tolerance of cowpea was evaluated by the relative reduction in shoot dry matter of each genotype. The genotype CE-182 had more tolerant levels of 2.5, 5.0 and $7.5 \mathrm{dS} \mathrm{m}^{-1}$ in saline water with $\mathrm{NaCl}$. In the solution mixture of salts, the genotypes and CE-9 and CE-551 were the most tolerant. According to the results obtained by clustering using the UPGMA method it can verified that the most promising combinations for crosses which obtained superior progenies in the development of cultivars tolerant to salinity were found between genotypes CE-182 and CE-250 and between $C E-551$ and $C E-9$.

Key words: Vigna unguiculata, genetic variability, multivariate analysis.

\section{INTRODUÇÃO}

Com a expansão do feijão-caupi, abrem-se novos mercados e perspectivas de comercialização para essa cultura, o que exigirá dos produtores a aplicação de manejo mais adequado para a garantia de um produto de qualidade e mais competitivo no mercado interno. A irrigação é uma das tecnologias aplicadas na agricultura que mais tem contribuído para o aumento na produção de alimentos. No caso do Nordeste, essa tecnologia é, muitas vezes, garantia de boa produtividade (ASSÍS JÚNIOR et al., 2007). No entanto, o uso inadequado dessa técnica vem provocando a salinização dos solos, principalmente nas condições ambientais do Nordeste (MURTAZA et al., 2006).

A salinidade provoca modificações morfológicas e metabólicas nas plantas (GONELA et al., 2006). A ação dos sais na agricultura, apesar de se refletir diretamente na produção das culturas, manifesta-se primeiramente na germinação das sementes (FURTADO et al., 2007). FAGERIAet al. (2010) afirmam que o feijão-caupi é considerado moderadamente tolerante a salinidade, podendo suportar, sem perdas expressivas na produção,

'Departamento de Fitotecnia, Centro de Ciências Agrárias (CCA), Universidade Federal do Ceará (UFC), Av. Mister Hull, 2799, 60356-001, Fortaleza, CE, Brasil. E-mail: weneragronomia @gmail.com. *Autor para correspondência. 
salinidade em torno de 4,9dS m${ }^{-1}$. DANTAS et al. (2002) relataram que o grau de tolerância dessa cultura ao estresse salino varia entre genótipos.

A busca por novas fontes de genes para a tolerância à salinidade deve ser constante. $\mathrm{Na}$ identificação de novos genótipos com fontes de tolerância, a utilização da variabilidade genética nos cruzamentos de grupos geneticamente divergentes representa importante estratégia para obter ganhos de seleção. De acordo com MOREIRA et al. (2009), a utilização de técnicas multivariadas é uma opção viável para essa finalidade, uma vez que permite múltiplas combinações de informações dentro da unidade experimental, através da discriminação do genótipo com base em uma variável complexa.

Diante do exposto, objetivou-se com este trabalho identificar genótipos tolerantes ao estresse provocado pela solução de $\mathrm{NaCl}$ e pela mistura de $\mathrm{NaCl}$, $\mathrm{CaCl}_{2} \mathrm{e} \mathrm{MgCl}_{2}$ na água de irrigação, nos estádios iniciais de desenvolvimento e indicar possíveis combinações entre genótipos, buscando progênies tolerantes à salinidade.

\section{MATERIAL E MÉTODOS}

Os experimentos foram conduzidos no período de outubro a novembro de 2009 , em casa de vegetação do Departamento de Fitotecnia do Centro de Ciências Agrárias da Universidade Federal do Ceará (CCA/UFC). Inicialmente, foi realizado um pré-ensaio com trinta genótipos de feijão-caupi, destes foram selecionados os dez genótipos mais tolerantes ao estresse salino ao nível de $10 \mathrm{dS} \mathrm{m}^{-1}$, sendo estes utilizados no presente trabalho.

O delineamento experimental utilizado foi o inteiramente casualizado, com os tratamentos dispostos em esquema fatorial 10x4 (genótipos $\mathrm{x}$ níveis de condutividade elétrica de irrigação, respectivamente) com quatro repetições, cada uma delas representada por seis copos descartáveis de $250 \mathrm{ml}$, contendo uma semente em cada. Os genótipos testados pertencem ao Banco de Germoplasma de feijão-caupi (BAGCaupi) doCCA/UFC (CE-09, CE-11, CE-31, CE-67, CE-70, CE88, CE-104, CE-182, CE-250 e CE-551) e apresentam características quanto ao porte, ciclo, cor da flor e da semente, na grande maioria deles, diferentes. Os níveis de condutividade elétrica da água de irrigação foram os seguintes: $0,2,5 ; 5,0 \mathrm{e} 7,5 \mathrm{dS} \mathrm{m}^{-1}$.

Foram conduzidos dois experimentos: no primeiro, os níveis de salinidade foram obtidos pela adição de $\mathrm{NaCl}$ e, no segundo experimento, os níveis de salinidade foram obtidos pela adição da mistura dos sais $\mathrm{NaCl}, \mathrm{CaCl}_{2} .2 \mathrm{H}_{2} \mathrm{O}$ e $\mathrm{MgCl}_{2} .6 \mathrm{H}_{2} \mathrm{O}$ na proporção de 7:2:1 na água de irrigação, sendo mantidas as mesmas condutividades elétricas do primeiro experimento. Para o preparo das soluções salinas nos dois experimentos, obedeceu-se a relação entre condutividade elétrica da água de irrigação e sua concentração $\left(\mathrm{mmol}_{\mathrm{c}} \mathrm{L}^{-1}=\mathrm{CE}_{\mathrm{a}}\right.$ 10), conforme RHOADES et al. (2000).

O material utilizado como substrato foi areia lavada, considerada inerte. Inicialmente, foi realizada a aplicação das soluções salinas no solo, por vaso, objetivando a indução dos níveis de salinidade e que a umidade do solo ficasse próxima a $75 \%$ da capacidade de campo. As plântulas permaneceram por um período de oito dias, sendo este o período necessário para o seu estabelecimento.

As características de tolerância/ suscetibilidade dos genótipos de feijão-caupi ao estresse salino avaliadas nos dois experimentos foram o comprimento da parte aérea (CPA), o comprimento da raiz (CR) e o diâmetro de caule (DC); a massa de matéria seca de parte aérea (MSPA) e a de raiz (MSR), realizada em estufa de ar forçado a $80^{\circ} \mathrm{C}$ por um período de 24h; emergência de plântula (EP), correspondendo ao número total de plântulas emergidas; índice de velocidade de emergência (IVE), correspondendo ao número de plântulas emergidas diariamente e tempo médio de emergência (TME). Essas avaliações foram realizadas no oitavo dia, período necessário para o estabelecimento das plântulas.

Os resultados obtidos para cada variável foram submetidos à análise de variância. Inicialmente, foram realizadas análises univariadas (teste $\mathrm{F}$ ) em todos os caracteres avaliados, considerando o efeito do genótipo como fixo. Observadas as diferenças significativas pelo teste $\mathrm{F}$, foi feito o teste de média de Scott \& Knott (SCOTT \& KNOTT, 1974) a 5\% de probabilidade.

Para a classificação dos genótipos quanto a sua tolerância ao estresse salino, foram observados os cálculos percentuais de desempenho relativo (aumento ou redução), considerando-se $100 \%$ o valor absoluto do tratamento não salinizado. Para isso, utilizou-se a fórmula proposta por FAGERIAet al. (2010), em que se avalia a redução da produção relativa de MSPA de cada genótipo, em cada nível de salinidade, em comparação com a produção de MSPA observada na água de irrigação não salinizada. Para proceder a essa classificação, foram adotados os seguintes intervalos de redução relativa de MSPA: tolerante, de zero a $20 \%$; moderadamente tolerante, de 21 a $40 \%$; moderadamente suscetível, de 41 a $60 \%$ e; suscetível, acima de $60 \%$. Essas perdas percentuais foram utilizadas como indexadores para comparar a tolerância dos diferentes materiais genéticos.

Em seguida, a partir dos dados de desempenho relativo de todas as características 
analisadas, foi realizada análise de dissimilaridade genética entre todos os pares de genótipos por meio da distância generalizada de Mahalanobis $\left(\mathrm{D}^{2}\right)$. Posteriormente, realizou-se uma análise multivariada, a análise de agrupamento, utilizando-se o método hierárquico UPGMA.

Para a estimativa do ajuste entre a matriz de dissimilaridade e o dendrograma gerado, utilizou-se o coeficiente de correlação cofenética (r), de acordo com a seguinte fórmula: $r_{c o f}=r_{D C}=\frac{C \hat{O} V(D, C)}{\sqrt{\hat{V}(D)} \hat{V}(C)}$ em queDrepresenta a matriz de distância e $\mathrm{C}$ a matriz cofenética, obtida a partir do dendrograma. O nível de significância da correlação foi avaliado utilizando-se a estatística $Z$ de Mantel (MANTEL, 1967) e a avaliação da significância de Z foi feita utilizando-se o programa GENES. Todas as análises estatísticas foram realizadas por meio do programa computacional GENES (CRUZ, 2006).

\section{RESULTADOS E DISCUSSÃO}

Foram observadas diferenças entre os genótipos e níveis de salinidade para todas as características avaliadas, porém não foi encontrado efeito de interação entre os fatores estudados, indicando que há variabilidade genética entre os genótipos e que os níveis salinos da água de irrigação exerceram influência na emergência e estabelecimento das plântulas.

Para as características avaliadas, houve diferenças nas médias entre os genótipos para CPA, DP, MSPA, MSR e TME nas soluções de $\mathrm{NaCl}$, porém no CR, IVE e EP não apresentaram diferenças significativas. Para o estresse submetido pelos sais $\mathrm{NaCl}, \mathrm{CaCl}_{2}$ e $\mathrm{MgCl}_{2}$, somente MSR e EP não diferiram entre os genótipos (Tabela 1).

Segundo SANTOS et al. (2009a), essas diferenças entre as soluções salinas são devido ao efeito tóxico dos íons variarem conforme a natureza dos sais. ORCUTT e NILSEN (2002) acrescentaram que o efeito iônico envolve interferências na absorção, assimilação e transporte de nutrientes.

$\mathrm{O}$ efeito da salinidade sobre o CPA e CR, segundo SANTOS et al. (2009a), é provavelmente devido à redução no crescimento da planta, causada pelo comprometimento de funções fisiológicas e

Tabela 1 - Médias de comprimento da parte aérea (CPA), comprimento de raiz (CR), diâmetro (D), índice de velocidade de emergência (IVE), massa seca da parte aérea (MSPA), massa seca da raiz (MSR), tempo médio de emergência (TME) e emergência (E) de genótipos de feijão-caupi na fase inicial de desenvolvimento em condição de estresse salino, provocado pela solução de $\mathrm{NaCl} e$ pela mistura dos sais $\mathrm{NaCl}, \mathrm{CaCl}_{2}$ e $\mathrm{MgCl}_{2}$.

\begin{tabular}{|c|c|c|c|c|c|c|c|c|}
\hline Genótipos & $\mathrm{CPA}(\mathrm{cm})$ & $\mathrm{CR}(\mathrm{cm})$ & $\mathrm{DP}(\mathrm{cm})$ & IVE & $\operatorname{MSPA}(\mathrm{g})$ & $\operatorname{MSR}(g)$ & TME (dias) & $\mathrm{EP}(\%)$ \\
\hline \multicolumn{9}{|c|}{ 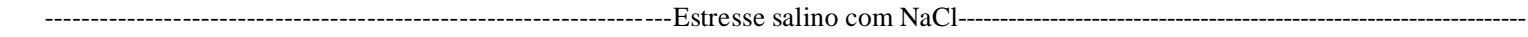 } \\
\hline CE-09 & $6,5 \mathrm{a}$ & $16,8 \mathrm{a}$ & $2,6 \mathrm{~b}$ & $1,0 \mathrm{a}$ & $0,09 b$ & $0,06 \mathrm{~b}$ & $5,80 \mathrm{~b}$ & $93,05 \mathrm{a}$ \\
\hline CE-11 & $5,6 \mathrm{a}$ & $15,5 \mathrm{a}$ & $2,8 \mathrm{a}$ & $1,1 \mathrm{a}$ & $0,1 \mathrm{a}$ & $0,05 \mathrm{c}$ & $5,43 \mathrm{~b}$ & $95,83 \mathrm{a}$ \\
\hline CE-31 & $6,1 \mathrm{~b}$ & $13,9 \mathrm{a}$ & $2,7 \mathrm{a}$ & $0,9 \mathrm{a}$ & $0,09 \mathrm{a}$ & $0,08 \mathrm{a}$ & $5,75 \mathrm{~b}$ & 83,33 a \\
\hline CE-67 & $5,6 \mathrm{~b}$ & $13,5 \mathrm{a}$ & $3,3 \mathrm{a}$ & $0,7 \mathrm{a}$ & $0,1 \mathrm{a}$ & $0,06 \mathrm{~b}$ & $6,42 \mathrm{a}$ & $72,22 \mathrm{a}$ \\
\hline CE-70 & $5,2 \mathrm{a}$ & $14,2 \mathrm{a}$ & $2,7 \mathrm{a}$ & $0,9 \mathrm{a}$ & $0,08 \mathrm{~b}$ & $0,06 \mathrm{~b}$ & $5,71 \mathrm{~b}$ & $88,88 \mathrm{a}$ \\
\hline CE-88 & $7,0 \mathrm{a}$ & $14,0 \mathrm{a}$ & $2,9 \mathrm{a}$ & $1,0 \mathrm{a}$ & $0,1 \mathrm{a}$ & $0,05 \mathrm{c}$ & $5,59 \mathrm{~b}$ & $90,28 \mathrm{a}$ \\
\hline CE-104 & $7,4 \mathrm{a}$ & $14,3 \mathrm{a}$ & $3,0 \mathrm{a}$ & $0,8 \mathrm{a}$ & $0,1 \mathrm{a}$ & $7,72 \mathrm{~b}$ & $5,94 \mathrm{~b}$ & $81,94 \mathrm{a}$ \\
\hline CE-182 & $5,9 \mathrm{~b}$ & $14,0 \mathrm{a}$ & $2,5 \mathrm{~b}$ & $0,8 \mathrm{a}$ & $0,09 \mathrm{~b}$ & $0,06 \mathrm{~b}$ & $6,30 \mathrm{a}$ & $76,39 a$ \\
\hline CE-250 & $5,5 \mathrm{~b}$ & $11,9 \mathrm{a}$ & $2,2 \mathrm{~b}$ & $1,1 \mathrm{a}$ & $0,07 \mathrm{~b}$ & $0,03 \mathrm{~d}$ & $5,35 \mathrm{~b}$ & $91,66 \mathrm{a}$ \\
\hline \multirow[t]{2}{*}{ CE-551 } & $6,6 \mathrm{a}$ & $12,0 \mathrm{a}$ & $2,4 \mathrm{~b}$ & $0,9 \mathrm{a}$ & $0,09 \mathrm{~b}$ & $0,05 \mathrm{c}$ & $5,77 \mathrm{~b}$ & $88,88 \mathrm{a}$ \\
\hline & & --------1 & e salino c & istura d & $\mathrm{NaCl}, \mathrm{CaC}$ & {$\left[\mathrm{gCl}_{2}\right.$} & (-2) & - \\
\hline CE-09 & $7,8 \mathrm{a}$ & $18,9 \mathrm{a}$ & $2,2 \mathrm{c}$ & $0,9 \mathrm{a}$ & $0,08 \mathrm{~b}$ & $0,10 \mathrm{a}$ & $5,83 \mathrm{~b}$ & $92,71 \mathrm{a}$ \\
\hline CE-11 & $6,4 \mathrm{~b}$ & $19,4 \mathrm{a}$ & $2,3 \mathrm{~b}$ & $1,1 \mathrm{a}$ & $0,11 \mathrm{a}$ & $0,11 \mathrm{a}$ & $5,49 \mathrm{~b}$ & $92,71 \mathrm{a}$ \\
\hline CE-31 & $6,9 \mathrm{~b}$ & $16,0 \mathrm{~b}$ & $2,3 \mathrm{~b}$ & $0,9 \mathrm{a}$ & $0,08 \mathrm{~b}$ & $0,12 \mathrm{a}$ & $5,81 \mathrm{~b}$ & $89,58 \mathrm{a}$ \\
\hline CE-67 & $7,7 \mathrm{a}$ & $16,9 \mathrm{a}$ & $2,7 \mathrm{a}$ & $0,7 \mathrm{~b}$ & $0,11 \mathrm{a}$ & $0,11 \mathrm{a}$ & $6,16 \mathrm{a}$ & $79,17 \mathrm{a}$ \\
\hline CE-70 & $6,8 \mathrm{~b}$ & $15,7 \mathrm{~b}$ & $2,3 \mathrm{~b}$ & $1,0 \mathrm{a}$ & $0,09 \mathrm{a}$ & $0,13 \mathrm{a}$ & $5,59 \mathrm{~b}$ & $94,79 \mathrm{a}$ \\
\hline CE-88 & $8,6 \mathrm{a}$ & $14,1 \mathrm{~b}$ & $2,1 \mathrm{c}$ & $1,1 \mathrm{a}$ & $0,09 \mathrm{a}$ & $0,13 \mathrm{a}$ & $5,43 \mathrm{~b}$ & $97,91 \mathrm{a}$ \\
\hline CE-104 & $7,8 \mathrm{a}$ & $14,1 \mathrm{~b}$ & $2,4 \mathrm{~b}$ & $0,8 \mathrm{~b}$ & $0,10 \mathrm{a}$ & $0,17 \mathrm{a}$ & $6,15 \mathrm{a}$ & $85,42 \mathrm{a}$ \\
\hline CE-182 & $7,0 \mathrm{~b}$ & $16,6 \mathrm{a}$ & $2,1 \mathrm{c}$ & $0,8 \mathrm{~b}$ & $0,08 \mathrm{~b}$ & $0,09 \mathrm{a}$ & $6,35 \mathrm{a}$ & $88,54 \mathrm{a}$ \\
\hline CE-250 & $6,8 \mathrm{~b}$ & $14,5 \mathrm{~b}$ & $1,7 \mathrm{~d}$ & $1,1 \mathrm{a}$ & $0,07 \mathrm{~b}$ & $0,13 \mathrm{a}$ & $5,27 \mathrm{~b}$ & $91,66 \mathrm{a}$ \\
\hline CE-551 & $8,3 \mathrm{a}$ & $12,6 \mathrm{~b}$ & $2,0 \mathrm{c}$ & $1,0 \mathrm{a}$ & $0,10 \mathrm{a}$ & $0,09 \mathrm{a}$ & $5,65 \mathrm{~b}$ & $92,71 \mathrm{a}$ \\
\hline
\end{tabular}

As médias seguidas pela mesma letra não diferem estatisticamente entre si, pelo teste de Scott-knott, em nível de 5\% de probabilidade. 
bioquímicas. Por outro lado, LACERDA et al. (2006) relatam que a redução na produção de massa seca de parte aérea e de raiz está associada aos efeitos osmóticos, tóxicos e nutricionais, decorrentes do acúmulo de sais na zona radicular da planta.

PRISCO (1980) esclarece que os sais na zona radicular da planta provocam redução da permeabilidade do sistema radicular à água, induzindo ao déficit hídrico, que, por consequência, leva à redução na taxa de fotossíntese e na taxa de crescimento. Além disso, quando as plantas são submetidas a esse estresse, os efeitos iniciais não causam sintomas visíveis, como toxicidade, injúrias, desbalanço nutricional ou desidratação, promovendo, no entanto, redução no crescimento (FAGERIA et al., 2010).

Dentre as alternativas utilizadas para avaliar o crescimento de plântulas, estão a EP, o IVE e o TME. O IVE e TME diferiram entre os genótipos, já a EP não divergiu entre os genótipos nos dois experimentos. Estudos desenvolvidos por MURILLO-AMADOR et al. (2006) demonstraram que o aumento da salinidade diminuiu a percentagem de emergência das plântulas, sendo esse efeito dependente do genótipo. No entanto, a emergência de plântulas é afetada dentro do genótipo, mas não entre genótipos (Tabela 1).

Dessa forma, estes resultados, provavelmente, são devido ao menor potencial osmótico, provocando redução no gradiente de potencial hídrico entre o solo e a semente, dificultando a absorção de água e retardando as atividades metabólicas, que, segundo MOTERLE et al. (2006), prejudicam o desempenho das sementes.

Na tabela 2, observa-se a classificação dos genótipos utilizando-se a fórmula proposta por FAGERIA et al. (2010). Considerando-se o nível de salinidade de $2,5 \mathrm{dS} \mathrm{m}^{-1}$, os genótipos foram classificados em tolerantes e moderadamente tolerantes. Quando o nível de salinidade passou para $5,0 \mathrm{dS} \mathrm{m}^{-1}$, a maioria dos genótipos foi classificada como moderadamente tolerante, com exceção dos genótipos CE-88 e CE-250, que foram moderadamente suscetíveis e, considerando-se o nível de maior salinidade $\left(7,5 \mathrm{dS} \mathrm{m} \mathrm{m}^{-1}\right)$, apenas o genótipo CE-182 mostrou-se moderadamente tolerante, enquanto que os demais foram classificados como moderadamente suscetíveis e suscetíveis.

As medidas de dissimilaridade genética, estimadas a partir da distância de Mahalanobis $\left(\mathrm{D}^{2}\right)$, apresentaram magnitude de 0,19 a 13,43 no experimento utilizando solução de $\mathrm{NaCl}$ e magnitude de 0,38 a 5,42 no experimento utilizando solução da mistura dos sais. Tais resultados indicam a presença de ampla variabilidade genética para tolerância à salinidade entre os genótipos estudados. Os genótipos mais similares, considerando-se o estresse provocado pela solução $\mathrm{de} \mathrm{NaCl}$, foram o CE-70 e o CE-104 ( $\left.\mathrm{D}^{2}=0,19\right)$ e os mais
Tabela 2 - Produção relativa de matéria seca de parte aérea (MSPA) de genótipos de feijão-caupi em condição de estresse com $\mathrm{NaCl}$ e com a mistura de $\mathrm{NaCl}$, $\mathrm{CaCl}_{2}$ e $\mathrm{MgCl}_{2}$ na água de irrigação.

\begin{tabular}{lccc}
\hline \multicolumn{4}{c}{ Desempenho relativo (\%) em função do } \\
Genótipo & \multicolumn{3}{c}{ tratamento não salinizado } \\
\multicolumn{4}{c}{5,0} \\
CE-09 & \multicolumn{4}{c}{-------------Estresse com NaCl------------- } \\
CE-11 & $25,42^{\mathrm{MT}}$ & $39,40^{\mathrm{MT}}$ & $54,00^{\mathrm{MS}}$ \\
CE-31 & $22,07^{\mathrm{MT}}$ & $37,88^{\mathrm{MT}}$ & $60,28^{\mathrm{S}}$ \\
CE-67 & $23,11^{\mathrm{MT}}$ & $36,06^{\mathrm{MT}}$ & $57,61^{\mathrm{MS}}$ \\
CE-70 & $10,67^{\mathrm{T}}$ & $31,57^{\mathrm{MT}}$ & $51,96^{\mathrm{MS}}$ \\
CE-88 & $10,58^{\mathrm{T}}$ & $38,51^{\mathrm{MT}}$ & $53,83^{\mathrm{MS}}$ \\
CE-104 & $21,81^{\mathrm{MT}}$ & $51,47^{\mathrm{MS}}$ & $51,32^{\mathrm{MS}}$ \\
CE-182 & $2,65^{\mathrm{T}}$ & $30,16^{\mathrm{MT}}$ & $55,83^{\mathrm{MS}}$ \\
CE-250 & $-4,27^{\mathrm{T}}$ & $20,11^{\mathrm{MT}}$ & $33,94^{\mathrm{MT}}$ \\
CE-551 & $25,83^{\mathrm{MT}}$ & $46,56^{\mathrm{MS}}$ & $62,13^{\mathrm{S}}$ \\
& $31,85^{\mathrm{MT}}$ & $37,04^{\mathrm{MT}}$ & $64,13^{\mathrm{S}}$ \\
& $--------\mathrm{Estresse}$ com a mistura dos sais-------- \\
CE-09 & $-2,74^{\mathrm{T}}$ & $18,26^{\mathrm{T}}$ & $29,22^{\mathrm{MT}}$ \\
CE-11 & $9,79^{\mathrm{T}}$ & $31,08^{\mathrm{MT}}$ & $39,19^{\mathrm{MT}}$ \\
CE-31 & $13,71^{\mathrm{T}}$ & $22,58^{\mathrm{MT}}$ & $63,71^{\mathrm{S}}$ \\
CE-67 & $-5,65^{\mathrm{T}}$ & $12,37^{\mathrm{T}}$ & $59,36^{\mathrm{MS}}$ \\
CE-70 & $17,09^{\mathrm{T}}$ & $21,09^{\mathrm{MT}}$ & $45,09^{\mathrm{MS}}$ \\
CE-88 & $22,82^{\mathrm{MT}}$ & $21,81^{\mathrm{MT}}$ & $49,66^{\mathrm{MS}}$ \\
CE-104 & $7,32^{\mathrm{T}}$ & $18,68^{\mathrm{T}}$ & $55,31^{\mathrm{MS}}$ \\
CE-182 & $31,17^{\mathrm{MT}}$ & $26,32^{\mathrm{MT}}$ & $47,37^{\mathrm{MS}}$ \\
CE-250 & $-12,57^{\mathrm{T}}$ & $18,86^{\mathrm{T}}$ & $46,86^{\mathrm{MS}}$ \\
CE-551 & $9,50^{\mathrm{T}}$ & $18,25^{\mathrm{T}}$ & $34,22^{\mathrm{MT}}$ \\
\hline
\end{tabular}

T: tolerante; MT: moderadamente tolerante; MS: moderadamente suscetível; S: suscetível.

distantes foram os genótipos CE-182 e CE-250 $\left(\mathrm{D}^{2}=13,43\right)$. Por outro lado, os genótipos mais similares, considerando-se o estresse provocado pela solução da mistura dos sais, foram o CE-31 e CE- $88\left(D^{2}=0,38\right)$ e os mais distantes foram os genótipos CE-182 e CE-551 $\left(\mathrm{D}^{2}=5,43\right)$.

O genótipo CE-182 apresentou a maior distância para quase todas as combinações no ensaio com solução de $\mathrm{NaCl}$, enquanto que o genótipo CE551 apresentou as maiores distâncias em todas as combinações quando utilizou-se a mistura de sais.

Os dendrogramas construídos com base na análise de agrupamento pelo método hierárquico UPGMA dos genótipos de feijão-caupi submetidos ao estresse, provocados pela solução de $\mathrm{NaCl}(\mathrm{r}=0,80)$ e pela mistura dos sais $(\mathrm{r}=0,78)$, podem ser observados, respectivamente, nas figuras $1 \mathrm{Ae} 1 \mathrm{~B}$.

$\mathrm{O}$ agrupamento dos genótipos submetidos ao estresse pelo $\mathrm{NaCl}$ permitiu a formação de três grupos (Figura 1A), considerando-se um ponto de corte na abscissa no penúltimo nível de fusão. O primeiro 
grupo contém os genótipos CE-9, CE-11, CE-67, CE-70, CE-88, CE-104, e CE-551; o segundo, os genótipos CE31e CE-250 e; o terceiro, o genótipo CE-182. A formação desses grupos representa uma valiosa informação na escolha de genitores dentro de um programa de melhoramento, pois, segundo BERTAN et al. (2006), as novas combinações híbridas a serem estabelecidas devem ser embasadas na magnitude de suas dissimilaridades. Entretanto, é importante enfatizar que a identificação das melhores combinações deve ser feita não somente baseada na divergência entre os genótipos, mas também em relação ao seu potencial agronômico e, no caso do presente trabalho, em relação à sua classificação quanto à tolerância a salinidade.

Portanto, as combinações entre os genótipos CE-182 e os genótipos CE-250 ( $\left.\mathrm{D}^{2}=13,43\right)$, CE-31 ( $\left.D^{2}=11,03\right)$ e CE-551 $\left(D^{2}=9,84\right)$ seriam as mais recomendadas por apresentarem as maiores dissimilaridades e melhor classificação quanto à tolerância a salinidade (Tabela 2).

$\mathrm{O}$ agrupamento dos genótipos submetidos ao estresse pela mistura dos sais permitiu a formação de três grupos (Figura 1B), considerando-se um ponto de corte na abscissa no penúltimo nível de fusão. Os genótipos CE-551 e CE-09 apresentaram as maiores distâncias em relação aos demais, ficando em grupos isolados. Os demais genótipos ficaram reunidos em um mesmo grupo. Os genótipos CE-09 e CE-551 apresentaram os valores mais baixos quanto à redução da produção relativa de MSPA (Tabela 2), sendo classificados como tolerantes a moderadamente tolerantes para os três níveis de salinidade avaliados.

Considerando-se os maiores valores de dissimilaridade e a classificação dos genótipos de acordo com a redução da produção relativa de MSPA, as melhores combinações para a formação de híbridos, levando-se em conta o estresse submetido pela mistura de sais, seriam entre os genótipos CE-551 e CE-182, CE-09.

Na comparação dos genótipos tolerantes ao estresse provocado pela solução de $\mathrm{NaCl}$ com os tolerantes ao estresse induzido pela mistura dos sais, a classificação em tolerante, moderadamente tolerante, moderadamente suscetível e suscetível diferiram entre si (Tabela 2). A diferença encontrada na classificação,

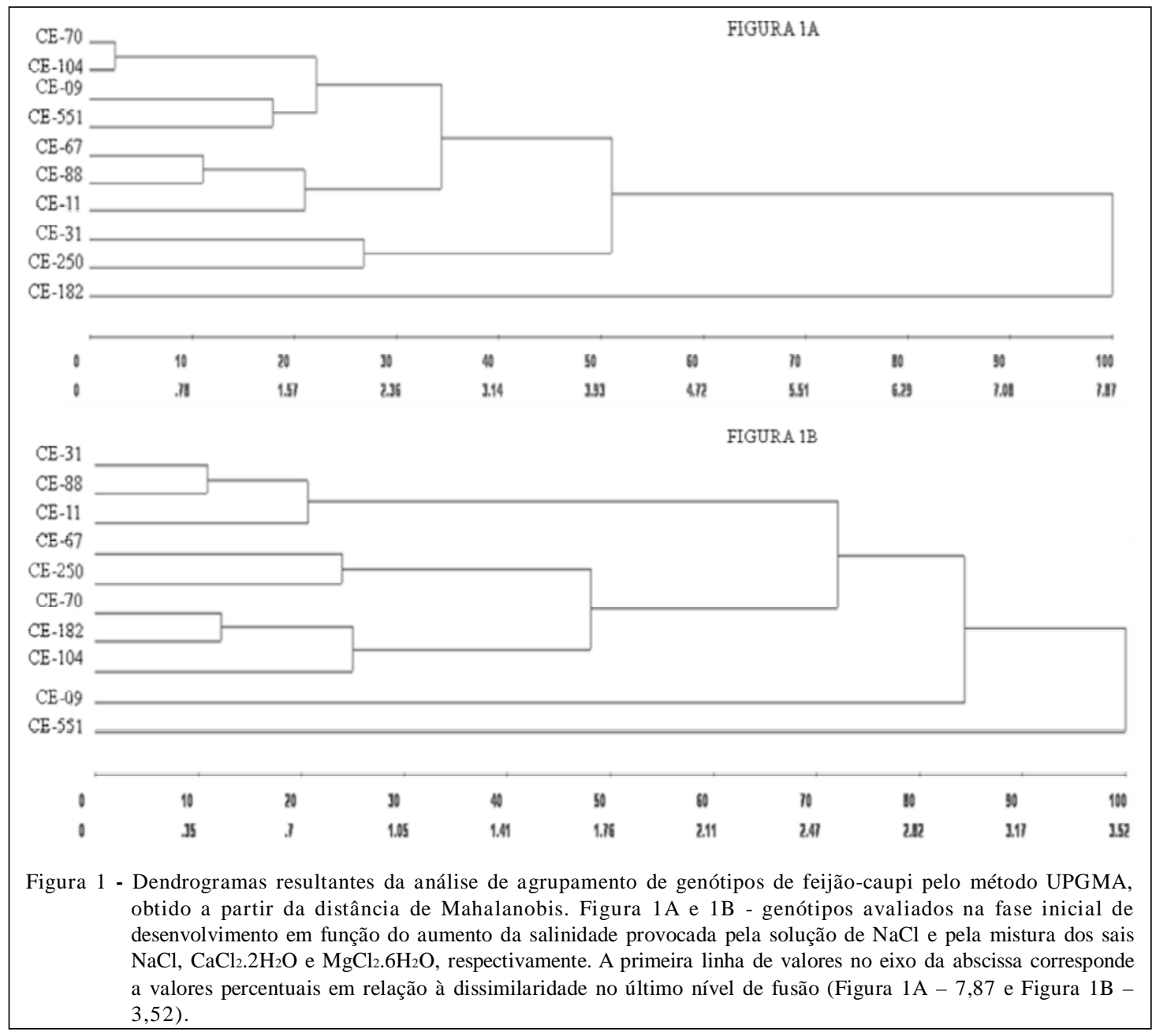

Ciência Rural, v.41, n.11, nov, 2011. 
de acordo com a composição iônica da água de irrigação, segundo ULLAH et al. (1993), é devido aos antagonismos iônicos em ambientes salinos, que são usualmente seguidos pelas deficiências nutricionais, portanto, a composição iônica é importante no que diz respeito à tolerância ao estresse salino. Nesse sentido, é importante a avaliação dos genótipos sob estresse induzido pela adição de $\mathrm{NaCl}$ como também pela mistura de sais.

\section{CONCLUSÃO}

O genótipo CE-182 mostrou-se mais tolerante à salinidade da água de irrigação provocada pela solução de $\mathrm{NaCl}$ nos níveis de 2,5; 5,0 e 7,5 $\mathrm{dS} \mathrm{m}^{-1} \mathrm{e}$, para a salinidade da água de irrigação provocada pela mistura de $\mathrm{NaCl}, \mathrm{CaCl}_{2}$ e $\mathrm{MgCl}_{2}$, os genótipos CE-9 e CE-551 foram considerados tolerantes. Recomenda-se a realização de cruzamentos entre os genótipos CE-182 e CE-250 e entre CE-551 e CE-09 para a obtenção de progênies superiores no desenvolvimento de cultivares tolerantes à salinidade.

\section{REFERÊNCIAS}

ASSÍS JÚNIOR, J.O. et al. Produtividade do feijão-de-corda e acúmulo de sais no solo em função da fração de lixiviação e da salinidade da água de irrigação. Engenharia Agrícola, v.27, n.3, p.702-713, 2007. Disponível em: <http://dx.doi.org/ 10.1590/S0100-69162007000400013>. Acesso em: 26 ago. 2011. doi: 10.1590/S0100-69162007000400013.

BERTAN, I. et al. Dissimilaridade genética entre genótipos de trigo avaliados em cultivo hidropônico sob estresse por alumínio. Bragantia, v.65, n.1, p.55-63, 2006. Disponível em: <http:/ /dx.doi.org/10.1590/S0006-87052006000100007>. Acesso em: 26 ago. 2011. doi: 10.1590/S0006-87052006000100007.

CRUZ, C.D. Programa genes: análise multivariada e simulação. Viçosa: UFV, 2006. p.175.

DANTAS, J.P. et al. Avaliação de genótipos de caupi sob salinidade. Revista Brasileira de Engenharia Agrícola e Ambiental, v.6, n.3, p.425-430, 2002. Disponível em: <http:/ /dx.doi.org/10.1590/S1415-43662002000300008>. Acesso em: 28 ago. 2011. doi: 10.1590/S1415-43662002000300008.

DANTAS, B.F. et al. Physiological response of cowpea seeds to salinity stress. Revista Brasileira de Sementes, v.27, n.1, p.144-148, 2005. Disponível em: <http://dx.doi.org/ 10.1590/S0101-31222005000100018>. Acesso em: 28 ago. 2011. doi: 10.1590/S0101-31222005000100018.

FAGERIA, N.K. et al. Melhoramento genético vegetal e seleção de cultivares tolerantes à salinidade. In: GHEYI, H.R. et al. Manejo da salinidade na agricultura: estudos básicos e aplicativos. Fortaleza: INCT Sal, 2010. Cap.13, p.205-218.

FURTADO, R.F. et al. Efeito da salinidade na germinação de sementes de algodão. Revista Ciência Agronômica. v.38, n.2, p.224-227, 2007. Disponível em: <http://redalyc.uaemex.mx/ src/inicio/ArtPdfRed.jsp?iCve=195317449016>. Acesso em: 28 ago. 2011. doi: 195317449016.
GONELA, A. et al. Tolerância salina em quatro variedades botânicas de Stylosanthes guianensis. Científica, v.34, n.1, p.99-106, 2006.

LACERDA, C.F. et al. Morpho-physiological responses of cowpea leaves to salt stress. Brazilian Journal Plant Physiology, v.18, n.4, p.455-465, 2006. Disponível em: <http:/ /dx.doi.org/10.1590/S1677-04202006000400003>. Acesso em: 28 ago. 2011. doi: 10.1590/S1677-04202006000400003.

MANTEL, N.A. The detection of disease clustering and a generalized regression approach. Cancer Research, v.27, p.209-220, 1967.

MOREIRA, R.M.P. et al. Potencial agronômico e divergência genética entre genótipos de feijão-vagem de crescimento determinado. Semina: Ciências Agrárias, v.30, supl.1, p.1051-1060, 2009.

MURILLO-AMADOR, B. et al. Effect of $\mathrm{NaCl}$ salinity in the genotypic variation of cowpea (Vigna unguiculata) during early vegetative growth. Revista Scientia Horticulturae, v.108, n.1, p.423-431, 2006. Disponível em: <http://www.sciencedirect.com/ science/article/pii/S0304423806000963>. Acesso em: 28 ago. 2011. doi: 10.1016/j. scienta.2006.02.010.

MURTAZA, G. et al. Irrigation and soil management strategies for using saline-sodic water in a cotton-wheat rotation. Agricultural Water Management, v.81, n.1, p.98-114, 2006. Disponível em: <http://www.sciencedirect.com/science/ article/pii/S0378377405001502>. Acesso em: 28 ago. 2011. doi: 10.1016/j.agwat.2005.03.003.

NEVES, A.L.R. et al. Acumulação de biomassa e extração de nutrientes por plantas de feijão-de-corda irrigadas com água salina em diferentes estádios de desenvolvimento. Ciência Rural, v.39, n.3, p.758-765, 2009. Disponível em: <http:// dx.doi.org/10.1590/S0103-84782009005000013>. Acesso em: 28 ago. 2011. doi: 10.1590/S0103-84782009005000013.

ORCUTT, D.M.; NILSEN, E.T. Physiology of plants under stress - Soil and biotic factors. New York: John Wiley, 2000. 398p.

PRISCO, J.T. Alguns aspectos da fisiologia do "stress" salino. Revista Brasileira de Botânica, v.3, n.1/2, p.85-94, 1980.

RHOADES, J.D. et al. Uso de águas salinas para produção agrícola. Campina Grande: UFPB, 2000. 117p.

SANTOS, P.R. et al. Acúmulo de cátions em dois cultivares de feijoeiro crescidos em soluções salinas. Revista Ceres, v.56, n.5, p.666-678, 2009a.

SANTOS, P.R. et al. Germinação, vigor e crescimento de cultivares de feijoeiro em soluções salinas. Revista Brasileira de Engenharia Agrícola e Ambiental, v.13, supl, p.882889, 2009b. Disponível em: <http://dx.doi.org/10.1590/S141543662009000700010>. Acesso em: 28 ago. 2011. doi: 10.1590/S1415-43662009000700010.

SCOTT, A.J.; KNOTT, M.A. A cluster analysis method for grouping means in the analysis of variance. Biometrics, v.30, n.3, p.507-512, 1974.

ULLAH, S.M. et al. Ion uptake, osmoregulation and plantwater relations in faba beans (Vicia faba L.) under salt stress. Die Bodenkultur, v.44, p.291-301, 1993. 